Research Paper:

\title{
The Predictive Model of Elderly Psychological Well-being Based on Personality With the Mediation of Self-care, Spiritual Experiences, and Death Anxiety
}

\author{
Ahmad Heidari ${ }^{1}$, Mokhtar Arefi $^{1^{*}} \mathrm{O}$, Hasan Amiri ${ }^{1} \mathrm{C}$
}

1. Department of Psychology and Counseling, Kermanshah Branch, Islamic Azad University, Kermanshah, Iran.

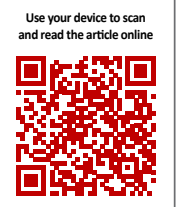

Citation Heidari A, Arefi M, Amiri H. The Predictive Model of Elderly Psychological Well-Being Based on Personality with the Mediation of Self-Care, Spiritual Experiences and Death Anxiety. Avicenna J of Neuropsychophysiology. 2019; 6(2):??. http:// dx.doi.org/10.32598/ajnpp.4.3.405

http://dx.doi.org/10.32598/ajnpp.4.3.405

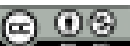

Article info:

Received: 03 Nov 2018

Accepted: 05 Mar 2019

Available Online: 01 May 2019

Keywords:

Personality disorder, Aged,

Self-care, Anxiety

\begin{abstract}
A B STRACT
Background: The aging population is undoubtedly an optimum success created by changes in mortality decline, as well as social and economic processes.

Objectives: The aim of this paper is to investigate the relationship between personality-based psychological well-being variables and the mediation of self-care, spiritual experiences, and death anxiety.

Materials and Methods: The statistical population of the present correlational study included all elderly individuals, who were being taken care of in private and public centers in Tehran, Iran, from 2017 to 2018. A total of 300 elderly people (76 males and 224 females) were selected by the systematic stratified random sampling method. Ryff's psychological well-being inventory, daily spiritual experiences scale, and NEO five-factor personality traits inventory were used to collect the data. The data were analyzed by SPSS V. 22 and Amos 22, using multiple regression, path analysis, and structural equation modeling.
\end{abstract}

Results: Personality variables (five-factor) predicted psychological well-being. Personality variables both directly and indirectly had a significant relationship with psychological well-being through spirituality and death anxiety.

Conclusion: The predictive model of elderly psychological well-being based on personality with the mediation of self-care, spiritual experiences, and death anxiety has fitness.

\section{Introduction}

$\mathrm{T}$ he aging population is undoubtedly an optimum success created by changes in mortality decline, as well as social and economic processes [1]. However, while life expectancy is steadily increasing, the realm of health has changed (for example, life expectancy and health) [2]. Moreover, although the population has increased, on the one hand, chronic age-related diseases have increased, on

* Corresponding Author:

Mokhtar Arefi, PhD.

Address: Department of Psychology and Counseling, Kermanshah Branch, Islamic Azad University, Kermanshah, Iran.

Tel: +98 (912) 1027896?

E-mail:m.arefi@iauksh.ac.ir 
the other hand. As a result, elderly people live with a disability for some years [3], including the emergence of neurological symptoms and mental illness, such as mood disorders. Depression is present in $50 \%$ of these elders that leads to disorder in physical and cognitive functioning [4].

Psychological well-being, as one of the key components of public health over the past 2 decades, has absorbed the attention of many psychologists and researchers, and extensive research has been conducted in this regard. Ryff [5] considered his model of psychological well-being an effort to grow and advance regarding the realization of one's potentials. In psychology, well-being is defined as the optimal functioning of a human being [6]. Autonomy, personal growth, purposefulness in life, mastery of the environment, having positive relationships with others, and self-accepting are the constituents of psychological well-being in the Ryff's model [7]. When individuals, who are healthy and have psychological well-being can cope with the problems and disadvantages, they need to choose solutions [8]. In another definition, psychological well-being means the manifestation of all of one's talents and it derives from the balance between positive and negative emotions and life satisfaction [9].

On the other hand, psychological well-being includes important principles that affecting emotions can influence all of the dimensions of human behavior and his/ her development, including physical and mental health, skill and educational development, social competence, and creation of positive relationships [10]. Given the importance of psychological well-being in optimizing one's life and problems and disabilities that are experienced by the elderly in old age, this variable should be more carefully considered and the effective factors should be identified and more appropriate programs should be designed to help improve the well-being of the elderly.

Another variable that can affect psychological wellbeing is the personality traits of individuals. Research has shown that personality traits are one of the major determinants of individuals' psychological well-being and an individual's personality is considered the most important factor affecting their adjustment and health [11]. Some studies showed a positive and significant relationship between the personality traits of extraversion, agreeableness, openness to experience, and conscientiousness with psychological well-being, and there was a negative and significant relationship between neuroticism and psychological well-being. In general, the impact of personality traits on behavior and cogni- tion is sometimes direct and without a mediator, and sometimes by affecting the mediating factors, it causes behavioral and cognitive consequences [12]. In addition, there is a significant relationship between the 5 big personality factors and dimensions of psychological well-being [13].

In addition, in several studies, the role of personality traits in self-care behavior was highlighted. Personality traits, especially openness, neuroticism, and conscientiousness, can lead to the improvement of the patient's sense of ability to inhibit illness and accept responsibility. In other words, these personality traits can influence self-care in individuals [14]. There is a negative and significant relationship between neuroticism and self-care behavior, and there is a positive and significant relationship between extroversion, agreeableness, and conscientiousness with self-care behavior. Openness did not show a significant relationship. Research indicates that self-care both directly and indirectly can also affect psychological well-being through personality traits [15].

Another variable that can affect older people's psychological well-being is spirituality. Spirituality and religion have an important role in people's lives, and these components appear more in the elder's lives [16]. Experts believe that beliefs and spirituality are more common among older people than other age groups and as they become older, considering spirituality and paying attention to it will be a stronger predictor of greater health, happiness, and life satisfaction [17]. Spiritual practices provide emotional meaning and support for older people [18]. Spiritual practices or religious handling act as an important defense mechanism against risk factors associated with clinical symptoms such as depression, especially in older people [19]. With respect to the theoretical backgrounds and studies that show the importance of spirituality in older age and research backgrounds confirming the relationship between spiritual experiences and psychological well-being in other groups, it can be expected that spiritual experiences in the elderly promote the level of psychological wellbeing in this group.

Another variable that is more prominent in older ages is death anxiety. Problems such as physical changes, weakness in front of illnesses, disability, and the loss of relatives and friends (mourning and lack) provide more evidence to think about death and the anxiety emerging from it during older ages [20]. Various factors can be effective in death anxiety and increase or decrease it. Spirituality and spiritual experiences are considered among the most effective factors in death anxiety in the elderly. 
Spiritual approaches determine how people deal with death, their perspective, and their understanding of death [21]. Religiosity has a significant correlation with death anxiety and religious beliefs can predict death anxiety more than the mere religious behavior [22] in elders suffering from chronic illnesses. Those, who have more religiosity and spirituality and have experienced a meaningful and purposeful life, are less afraid of death and are more likely to accept death [23]. Another factor related to death anxiety is personality traits. A different study showed a relationship between personality traits and death anxiety [24].

The aging process of the population in recent years has increased and the multiplicity and variety of stresses that individuals face in old age make it a requirement to pay attention to mental health and psychological wellbeing in old age. In order to achieve a comprehensive and effective program to promote psychological wellbeing in the elderly, it is necessary to do research and find effective and related factors to design the best and the most comprehensive program to help promote the psychological well-being in the elderly. Research literature indicates that limited research has been conducted in this field in the country and there is a necessity to further research. Regarding this fact, this study aims at predicting the psychological well-being of the elderly based on personality with the mediation of self-care, spiritual experiences, and death anxiety.

\section{Materials and Methods}

The statistical population of the present correlational study included all elderly individuals, who were being taken care of in private and public centers in Tehran, Iran, in 2017-2018. A total of 300 individuals were selected, using a systematic stratified sampling method. The number of the sample was determined based on Stevenson's suggestion [25] and at least 15 members were selected per direct path in the study sample. The inclusion criteria included age range of 60 years or older, and the lack of disorder or any other physical illnesses during the research. The exclusion criteria also included the age ranges of younger than 60 years, the history of a physical illness, and the provision of incomplete information. The participants completed the questionnaires. As the ethical considerations of the present study, all individuals received oral information about this research and, if desired, they participated in the research. The participants were assured that all information would be confidential and used only for research purposes. Also, in order to take into account their privacy, their names and surnames were not recorded.

\section{Ryff's Psychological Well-Being Inventory}

This questionnaire contains 18 items and its purpose is to evaluate psychological well-being from various dimensions (independence, mastery of the environment, personal growth, positive relationship with others, purposefulness in life, and self-acceptance). The results of the single-group confirmatory factor analysis showed that in the whole sample and in both sexes, the 6-factor model of this scale (self-acceptance, environmental mastery, positive relationship with others, purposefulness in life, personal growth, and independence) has an appropriate fit [5]. The internal correlation of this scale, using Cronbach's alpha regarding 6 factors of self-acceptance, environmental mastery, positive relationship with others, purposefulness in life, personal growth, and independence, were $0.51,0.76,0.75,0.52$, $0.73,0.72$, and 0.72 , respectively; it was also 0.71 for the whole scale [13].

\section{NEO Five-Factor Personality Traits Inventory}

NEO inventory is one of the newest questionnaires related to the evaluation of personality construct based on a factor analysis perspective. It has global utility and to be used in research, it has currently been translated into Czechoslovakian, Arabic, Dutch, French, German, Japanese, Norwegian, Polish, and Swedish languages. The NEO five-factor personality traits inventory was administered onto 208 American university students over a 3-month period by McCrae and Costa and got a reliability coefficient ranged $0.75-0.83$. The reliability coefficient of the 5 main dimensions was $0.56-0.87$. The Cronbach's alpha coefficient in each of the main factors of neuroticism, extroversion, openness, agreeableness, and conscientiousness were $0.86,0.73,0.56,0.68$, and 0.87 , respectively [22]. In order to evaluate the content validity of this test, the correlation between two forms of the subjective report (s) and observer evaluation form (R) was used. The highest correlation rate of 0.66 was related to the factor of extroversion and the lowest correlational rate of 0.45 was related to the adjustment factor [24].

\section{Underwood and Teresi's Daily Spiritual Experiences Scale}

The daily spiritual experiences scale was developed by Underwood and Teresi. It is used to measure one's perception of a superior force in daily life and his/her perception of his/her interaction with this supernatural being. The correlation of spiritual experiences was related to higher scores in the short scale quality of life. Un- 
derwood [25] indicates a correlation coefficient of 0.85 for retest reliability. In a study, Loustalot et.al [26] investigated the internal consistency, using Cronbach's alpha, in which the values of 0.94 and 0.95 were obtained. The internal consistency, using Cronbach's alpha, was 0.88 for the test and 0.92 for the retest. The study by Underwood [25] showed that Cronbach's alpha for the first and second implementations of the scale were 0.86 and 0.90 , respectively.

\section{Robert and Glasgow Diabetes Self-Care Questionnaire}

Questions in this questionnaire allow individuals to report the quality of their self-care activities regarding their diabetes during the past 7 days. Having a healthy diet, injecting insulin or the correct usage of the pill, testing blood sugar, exercise, taking care of feet, and smoking behaviors are among these behaviors. A score of zero was be given to a person, who had no self-care behavior in the fields mentioned in the past 7 days, and a score of 70 was given to the person, who had self-care behaviors in 7 past days and on a daily basis. In order to determine the desirability level of self-care status, in addition to the scale of mean scores, the scores ranged from zero to 70 and it was divided into 3 parts, and one overall compliance score was obtained by adding the scores for each question. The value of Cronbach's alpha was 0.66 for the construct of self-care behaviors in the initial study; it was 0.68 in the total sample, and the equivalent reliability of 0.75 was obtained [27].

\section{Templar Death Anxiety Inventory}

This questionnaire was developed by Templer. It contains 15 true-false questions, which measures the attitudes of the subjects to death. The subjects determine their answers to each question with Yes or No options. Yes indicates anxiety in the individual. Therefore, the scores on this scale can range from zero to 15 , and a higher score indicates a higher level of death anxiety. This scale has 5 dimensions and in order to obtain scores of each dimension, we add points for each of its questions [28]. The reliability of the questionnaire was 0.87 , using the test-retest method. The content and face validity of the questionnaire were also approved by experts' opinions. In this study, Cronbach's alpha was 0.79 [29].

Descriptive and inferential statistics (Mean \pm SD and correlation) were used for data analysis. In order to investigate the fitness of the proposed model, an analysis of the underlying assumptions of structural equation modeling, as well as the extensive analysis, was performed. The analyses were conducted through path analysis and structural equation modeling. In order to investigate the indirect relationship between the paths, the Bootstrap Macro Method was used. All analyses were performed, using SPSS V. 22 and AMOS Torque V. 22.

\section{Results}

The Mean \pm SD of participants was $65.79 \pm 27.82 ; 76$ (25.3\%) of the participants were females and 224 (74.6\%) were males (Table 1). According to Table 2, the standard path coefficients of the personality variable on psychological well-being was 0.48 , $\mathrm{T}$ was 5.427 , and $\mathrm{P}$ value was less than 0.05 . Therefore, regarding the perspective of the research participants, personality had a significant and direct effect on the psychological wellbeing of the elderly.

According to Table 3, the direct effect of personality on the psychological well-being of the elderly was 0.48 , the direct effect of self-care effect on the psychological wellbeing of the elderly was 0.14 , the indirect effect of personality on psychological well-being through (the route of) self-care was 0.0532, and the total effect between these two variables was 0.553 . The Sobel was 2.277 and P-value was less than 0.05 ; therefore, personality through the mediation of self-care had a direct impact on the psychological well-being of the elderly.

According to Table 4, the direct effect of personality on the psychological well-being of the elderly was 0.48 , the direct effect of spiritual experiences on the psychological well-being of the elderly was 0.21 , the indirect effect of personality on psychological well-being through (route of) spiritual experiences was 0.598 , and the total effect between these two variables was 0.555 . The Sobel was 2.318 and the P-value was less than 0.05; thus, personality through the mediating role of spiritual experiences had a direct effect on the psychological wellbeing of the elderly.

According to Table 5, the direct effect of personality on the psychological well-being of the elderly was 0.48 , the direct effect of death anxiety on the psychological wellbeing of the elderly was -0.21 , the indirect effect of personality on psychological well-being through (route of) death anxiety was 0.063 , and the total effect between these two variables was 0.543 . The Sobel was 2.696 and the P-value was less than 0.05; therefore, personality with the mediating role of death anxiety had a direct impact on the psychological well-being of the elderly.

According to Table 6 and Figure 1, the Chi-square of the model was 2957.287, the degree of freedom of the 
Table 1. The Mean $\pm S D$ of the variables

\begin{tabular}{|c|c|c|c|c|}
\hline & Variables & Mean士SD & Min. & Max. \\
\hline \multirow{6}{*}{ 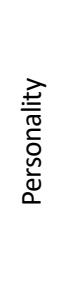 } & Neurosis & $24.04 \pm 10.96$ & 0.00 & 48.00 \\
\hline & Extroversion & $27.91 \pm 10.68$ & 0.00 & 48.00 \\
\hline & Openness to experience & $29.77 \pm 10.78$ & 0.00 & 48.00 \\
\hline & Agreeableness & $34.07 \pm 10.58$ & 0.00 & 48.00 \\
\hline & Accountability & $33.49 \pm 11.29$ & 0.00 & 48.00 \\
\hline & Personality type & $149.28 \pm 32.04$ & 48.00 & 240.00 \\
\hline \multirow{7}{*}{ 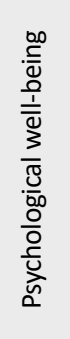 } & Independence & $10.36 \pm 4.59$ & 3.00 & 18.00 \\
\hline & Environmental mastery & $11.04 \pm 4.35$ & 3.00 & 18.00 \\
\hline & Personal growth & $10.51 \pm 4.64$ & 3.00 & 18.00 \\
\hline & Positive relationship with others & $10.77 \pm 4.64$ & 3.00 & 18.00 \\
\hline & Purposefulness in life & $10.38 \pm 4.41$ & 3.00 & 18.00 \\
\hline & Self-acceptance & $10.69 \pm 4.61$ & 3.00 & 48.00 \\
\hline & Psychological well-being & $63.74 \pm 17.48$ & 23.00 & 102.00 \\
\hline \multirow{6}{*}{ 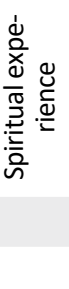 } & Feeling God's presence & $31.65 \pm 10.09$ & 8.00 & 48.00 \\
\hline & Relation with God & $20.26 \pm 6.15$ & 5.00 & 30.00 \\
\hline & Accountability regarding others & $12.14 \pm 3.66$ & 3.00 & 18.00 \\
\hline & Spiritual experience & $64.05 \pm 15.47$ & 24.00 & 96.00 \\
\hline & Death anxiety & $7.14 \pm 6.21$ & 0.00 & 15.00 \\
\hline & Self-care & $48.61 \pm 25.81$ & 0.00 & 98.00 \\
\hline
\end{tabular}

Table 2. Reviewing the hypothesis of research based on path analysis

\begin{tabular}{ccc}
\hline Studying the Direct Relationship Between Variables of the Model & Standard Coefficients & T \\
\hline Personality on psychological well-being & 0.48 & 5.427 \\
\hline
\end{tabular}

model was 1878 , and the sum of their ratio was 1.575 , which is an acceptable value. The RMSEA value was 0.044 and, on the other hand, the model fit indices such as CFI and IFI were all at an acceptable and appropriate level, and the index of SRMR was 0.0518 .

\section{Discussion}

Because of the tendency to have a relationship with others and enjoy the interaction with others, regardless of their age, extroverted elders are more motivated to work and more confident in their abilities [25]. This attribute leads to obtaining more success in life and having more emotional and social support from others and

Table 3. The mediating role of self-care in the impact of personality on psychological well-being based on the Sobel method

\begin{tabular}{ccc}
\hline Type & Standard Coefficients & Sobel Statistics \\
\hline The direct effect of personality on psychological well-being & 0.48 \\
The direct effect of self-care on psychological well-being & 0.14 \\
The indirect effect of personality on psychological well-being from \\
self-care route \\
Total effect
\end{tabular}


Table 4. Investigating the mediating role of spiritual experiences in the impact of personality on psychological well-being based on the Sobel method

\begin{tabular}{|c|c|c|c|}
\hline Type & Standard Coefficients & Sobel Statistic & $\mathbf{P}$ \\
\hline The direct effect of personality on psychological well-being & 0.48 & & \\
\hline The direct effect of spiritual experiences on psychological well-being & 0.21 & 2.318 & 0.020 \\
\hline $\begin{array}{c}\text { The indirect effect of personality on psychological well-being from the } \\
\text { route of spiritual experiences }\end{array}$ & 0.0798 & & \\
\hline Total effect & 0.5598 & & \\
\hline
\end{tabular}

AJNPP

Table 5. Investigating the mediating role of death anxiety regarding the impact of personality on psychological well-being based on the Sobel method

\begin{tabular}{|c|c|c|c|}
\hline Type & Standard Coefficients & Sobel Statistic & $\mathbf{P}$ \\
\hline The direct effect of personality on psychological well-being & 0.48 & & \\
\hline The direct effect of death anxiety on psychological well-being & -0.21 & 2.696 & 0.007 \\
\hline $\begin{array}{c}\text { The indirect effect of personality on psychological well-being from the } \\
\text { route of death anxiety }\end{array}$ & 0.063 & & \\
\hline Total effect & 0.543 & & \\
\hline
\end{tabular}

AJNPP

encourages positive emotions and a happy mood in the individual [26]. It is evident that a high level of such traits correlates with a higher score on psychological well-being.

Owing to its relationship with anxiety, depression, and other psychological and physical abnormalities, neuroticism activates negative emotions and feelings in the individual and prohibits the positive emotions that play a central role in psychological well-being. It is replaced by negative emotions and, as a result, reduces one's psychological well-being. Neurotic negatively predicted all psychological well-being components and Lau et al. [29] reported all aspects of psychological well-being with mood neuroticism. Mood neuroticism refers to one's desire to experience anxiety tension in return for hostility, low depression, and self-esteem, as well as individuals, whose neuroticism is stronger than other personality traits.

Table 6. Fit indices of the main research model

\begin{tabular}{cccc}
\hline Indices & Admissible Value & Research Findings Value & Model \\
\hline Chi-square $X^{2}$ & - & 2957.284 & Confirmed \\
\hline $\mathrm{P}$ & - & 0.000 & Confirmed \\
\hline $\mathrm{Df}$ & $\mathrm{df} \geq 0$ & 1878 & Confirmed \\
$X^{2} / \mathrm{df}$ & $X^{2} / \mathrm{df}<3$ & 1.575 & Confirmed \\
\hline $\mathrm{RMSEA}$ & $\mathrm{RMSEA}<0.1$ & 0.044 & Confirmed \\
\hline $\mathrm{NFI}$ & $\mathrm{NFI}>0.8$ & 0.795 & Not confirmed \\
\hline $\mathrm{AGFI}$ & $\mathrm{AGFI}>0.8$ & 0.759 & Not confirmed \\
\hline $\mathrm{GFI}$ & $\mathrm{GFI}>0.8$ & 0.776 & Not confirmed \\
\hline $\mathrm{CFI}$ & $\mathrm{CFI}>0.8$ & 0.914 & Confirmed \\
\hline $\mathrm{IFI}$ & $\mathrm{IFI}>0.8$ & 0.914 & Confirmed \\
\hline $\mathrm{TLI}$ & $\mathrm{TLI}>0.8$ & 0.910 & Confirmed \\
\hline $\mathrm{SRMR}$ & Closer to zero & 0.0518 & Confirmed \\
\hline
\end{tabular}




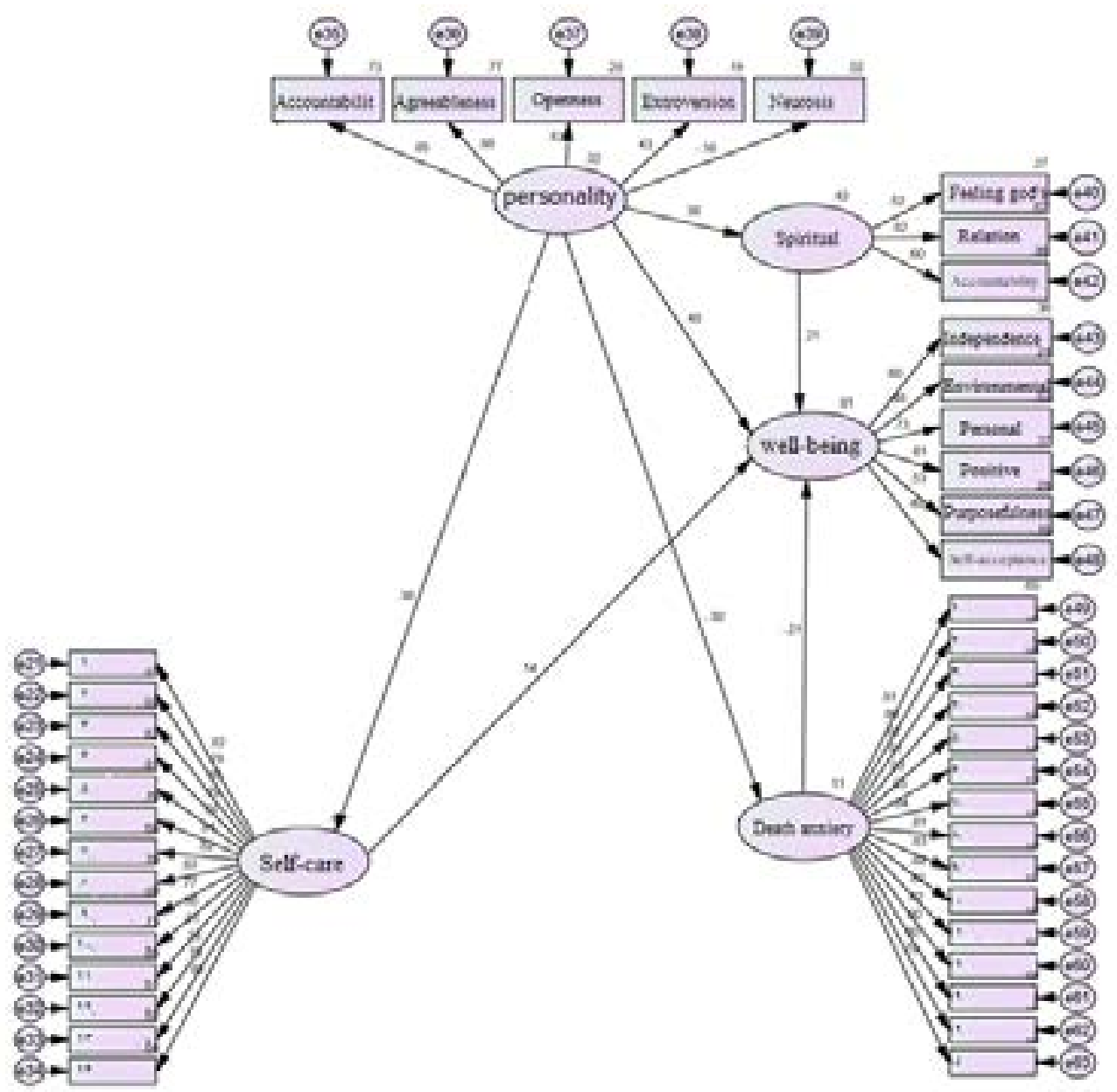

Chi_Square-2957.284; DF=1875; P.VALUE=.000; GF $=, 776 ; C F I=, 914 ; R M S E A=, 044$

Figure 1. Fitness of the main research model

Neurotic people look at what they have or what is happening around them with a negative assessment, interpretation, and conclusion; so, such traits can limit their social relationships in a circle or cause harm, slow down its prosperity, pave the grounds for his/her weakness, undermine the prospect of achieving successful identity, discourage people in favorable conditions for growth and development, and undermine psychological well-being. The study of trait acceptance has also predicted all components of environmental mastery of the autonomy, relationships with others, personal growth, purposefulness in life, and self-acceptance in a positive way. Acceptance refers to one's desire for curiosity, love of art and craftsmanship, flexibility, and self-discipline. Such a finding reminds the fact that when this trait is strong enough in individuals, it can affect a wide range of social relationships and can lead to good academic performance, as well as the growth of self-efficacy beliefs.
The results of the study showed that extraversion predicts self-acceptance, individual and environmental growth components depending on and referring to one's willingness to being positive, power-seeking, and being energetic and intimate. Extroverts are sociable and outgoing and the more the social network is expanded, the more the psychological well-being will increase [30].

There is a positive and significant relationship between self-care and the psychological well-being of the elderly. One of the goals of the self-care program is to increase people's knowledge and awareness of their condition. Various factors increase self-care in older people and it is important to pay close attention to these factors. Family support, self-efficacy and self-awareness literacy, and self-management are considered the reasons for this problem. The higher level of self-care in elderly residents in the family is because of social support and self-efficacy of the elderly, which enable them to cope better with their reduced physical and mental perfor- 
mances. Kometer et al. [31] argued that a living environment, in which elders live with their family, establishes the required communication and social interaction and helps them understand their abilities and maintain their self-care. Kesebir et al. [32], on the other hand, argued that the shared notion of self-care companionship with self-efficacy of social support is one of the most important predicted factors on the elderly's self-care.

The research model showed that the developed model fits well with the collected data. This finding is in line with the findings emphasizing the role of spirituality in explaining psychological well-being and death anxiety [31]. The satisfactory model fitted with the observed data can be explained as follows. Based on the conducted research and by accepting the assumption of the influence of spiritual activities and rituals, other factors such as social support can explain these effects. In addition, the fitting of the present research model is in line with Karam et al.'s study [33], in which the dimensions of the spiritual/religious semantic system, through intermediaries such as the meaning of life and social support, affect people's health. Also, the tested model of the present study is in line with the conceptual model of Iverach [34], which shows the relationship among the dimensions of religious experience, religious practices, spiritual beliefs, and the community of faith with biological, psychological, and social dimensions (3 dimensions of health).

The results of this study showed that spirituality has a significant and direct effect on mental health; that is, as scores of spirituality increase, the general health scores increase, given that a higher score on the general health questionnaire indicates sickness. This finding is in line with the results of numerous studies demonstrating the use of spiritual/religious inclinations for the public and psychological health of the elderly. According to these studies, higher spiritual beliefs are related to the lower levels of psychological distress [34]. By investigating the previously conducted studies in this regard, we can categorize the mechanisms of the effect of spirituality on psychological well-being into individual and social categories. Accordingly, the individual mechanisms of spirituality's effectiveness on mental health include in creased feelings of gratitude, purposefulness in life, and post-traumatic growth. These mechanisms reduce the impact of adverse events in life [35], create a positive attitude to the world, give meaning to one's life [36], impact on lifestyle [22], resolve value conflicts, answer basic human questions about the purpose of life, the meaning of activities, and the status of the individual in the world, overcome and give meaning to the underly- ing suffering and conflict of life [14] which increases the unity of the psychological, spiritual, and self-regulation [16], more adjustment with adverse life events, creating hope and motivation in life and increasing the feeling of control through praying [19].

The mediator of reliance on adaptive mechanisms [20], coping with stressful events, using spirituality as a coping strategy [23], and reducing anxieties associated with adverse situations result from the belief that the situation is controlled by God or a superior force. This problem makes spiritual people believe that we can control uncontrollable situations by relying on God [29] Increasing individual responsibility regarding spiritual and religious principles and beliefs have also physical effects [37]. Thus, it seems that the source of control regarding the relationship between spirituality and mental health play a mediating role.

People with a higher spirituality believe that superior forces or God give them power and authority to have an impact on their own circumstances, including their health. In such cases, they hold themselves accountable and by employing active coping strategies, they promote their physical and mental health. Social networks and support are the most important social factors and mechanisms regarding the impact of spirituality. Spiritual support, spiritual institutions, and spiritual networks are considered the most important factors in preventing disease [38]. The mechanisms, through which social support affects the relationship between spirituality and health of elderly people, can be summarized in this way: spiritual support increases the feelings of controlling in the elderly and reinforces the application of adaptive coping mechanisms; social/spiritual supports backs individuals in the face of social isolation, improve family and social networks, increases the elder people's sense of belonging and self-esteem, and impacts health-promoting lifestyle through spiritual teachings [39].

In addition, the model tested in the present study also implicitly confirms the theory of fear management by confirming the relationship between spirituality and death anxiety. When people, in particular elderly ones, are faced with death reminders, such as the death of loved ones and illnesses without a cure, their death anxiety will increase [40]. Elderly people, who have a higher spirituality, reduce their death anxiety through having more positive evaluations of the individuals, having views that support these values, reinforcing the protecting values, and joining spiritual networks. Also, having faith in a worldview and dignity derived from it provides protection and anxiety for the elderly. 
During the middle and old age, finding meaning in life becomes prominent for individuals, spirituality/religion owing to providing hope to symbolic immortality, and the immortality of thoughts that protect the elderly in front of death anxiety [41]. Also, spirituality in the elderly brings about the maintenance of identity integrity, psychological well-being, finding meaning in life, an increase of happiness, life satisfaction, and so on. This topic, in turn, increases life satisfaction in the elderly and helps to accept death and post-mortem life. Higher religiosity and spirituality have a relationship with less fear of death and its acceptance [42].

In the present study, there is a negative relationship between the source of internal control and death anxiety; that is, the more spiritual people seem to have a higher source of internal control, the less they experience death anxiety. It seems that spirituality gives a person a kind of attitude regarding understanding events from the point of fate or a natural force (the source of external control). On the other hand, by creating a sense of control over one's own life (the internal source of control), it can lead people to believe that by relying on God, one can take control of uncontrollable situations. Thus, by creating a sense of integrity and purposefulness in people's lives, it forms the basis for their cooperation and achievement of common goals.

Participation in spiritual or religious groups results in the belonging of people to networks of the same thinking people, who can help each other when needed [40]. The mediating role of social support regarding the relationship between spirituality and death anxiety can also be explained through the theory of fear management. Based on the relationship of spirituality with mental health and death anxiety, the theory of fear management, which is the best way to be defend against the horror of death and demise according to the basic characteristic of human acculturation, is seen as investing in a system of values (within its accepted culture) [42].

Increasing social/spiritual communication and, consequently, increasing spiritual/social support whether on the part of present individuals in the spiritual community or from the part of the family is related to protection in front of anxiety. This issue through the promotion and strengthening of self-esteem reduces anxiety and anxiety-related behaviors in the elderly. The present study was a cross-sectional one [40].

The present study was conducted on elderly people in Tehran and because of the cultural differences, it cannot be generalized to the elderly people in other cit- ies in Iran. Another limitation of this study was a large number of questions in questionnaires. Although the shortest form of any scale was chosen, it was out of the patience of the elderly. Moreover, the lower level of education of the elderly was also a reason. One of the limitations of this study was the little sample size that could affect its generalizability. Therefore, it is suggested that larger sample size should be used in future studies. Also, the selection of participants through the available sampling method can threaten the external validity of the research; therefore, it is recommended that future studies should best be selected randomly in order to increase the external validity of the samples. Other limitations include the type of research. This is a descriptive correlational study, from which causal relationships cannot be derived.

The predictive model of elderly psychological well-being based on personality with the mediation of self-care, spiritual experiences, and death anxiety has fitness.

\section{Ethical Considerations}

\section{Compliance with ethical guidelines}

All ethical principles were considered in this article. The participants were informed about the purpose of the research and its implementation stages and signed the informed consent. They were also assured about the confidentiality of their information; moreover, they were allowed to leave the study whenever they wish and, if desired, the results of the research would be available to them. This research has a code of ethics committee IR.IAUKSH.REC.1397.012.

\section{Funding}

This research did not receive any specific grant from funding agencies in the public, commercial, or not-forprofit sectors.

\section{Authors' contributions}

All authors contributed equally in preparing all parts of the research.

\section{Conflict of interest}

The authors declared no conflict of interest. 


\section{References}

[1] Zhao H, Seibert SE, Lumpkin GT. The relationship of personality to entrepreneurial intentions and performance: $A$ metaanalytic review. Journal of Management. 2010; 36(2):381-404. [DOI:10.1177/0149206309335187]

[2] Zaleskiewicz T, Gasiorowska A, Kesebir P, Luszczynska A, Pyszczynsk T. Money and the fear of death: The symbolic power of money as an existential anxiety buffer. Journal of Economic Psychology. 2013, 36:55-67. [DOI:10.1016/j.joep.2013.02.008]

[3] Youyou W, Kosinski M, Stillwell D. Computer-based personality judgments are more accurate than those made by humans. Proceedings of the National Academy of Sciences. 2015; 112(4):103640. [DOI:10.1073/pnas.1418680112] [PMID] [PMCID]

[4] Youssef-Morgan CM, Luthans F. Psychological capital and well-being. Stress and Health. 2015; 31(3):180-8. [DOI:10.1002/smi.2623] [PMID]

[5] Winefield HR, Gill TK, Taylor AW, Pilkington RM. Psychological wellbeing and psychological distress: Is it necessary to measure both? Psychology of Well-being: Theory, Research and Practice. 2012 Dec;2(1):3. [DOI:10.1186/2211-1522-2-3]

[6] Widiger TA, Costa PT. Integrating normal and abnormal personality structure: The five-factor model. Journal of Personality. 2012 80(6):1471-506. [DOI:10.1111/j.1467-6494.2012.00776.x] [PMID]

[7] Twenge JM. More time on technology, less happiness? Associations between digital-media use and psychological well-being. Current Directions in Psychological Science. 2019; 0963721419838244 [DOI:10.1177/0963721419838244]

[8] An E, Lo C, Hales S, Zimmermann C, Rodin G. Demoralization and death anxiety in advanced cancer. Psycho-oncology. 2018; 27(11):2566-72. [DOI:10.1002/pon.4843] [PMID]

[9] Stamps J, Groothuis TG. The development of animal personality: Relevance, concepts and perspectives. Biological Reviews. 2010; 85(2):301 25. [DOI:10.1111/j.1469-185X.2009.00103.x] [PMID]

[10] Sharpley R, Jepson D. Rural tourism: A spiritual experience? Annals of Tourism Research. 2011; 38(1):52-71. [DOI:10.1016/j.annals.2010.05.002

[11] Schuett W, Tregenza T, Dall SR. Sexual selection and animal personality. Biological Reviews. 2010; 85(2):217-46. [DOI:10.1111/ j.1469-185X.2009.00101.x] [PMID]

[12] Salgado AB. Theories of personality. In: Introductory Psychology for Nursing and Allied Health Sciences. Jaypee Brothers Medica Publishers (P) LTD: New Delhi; 2010. [DOI:10.5005/jp/books/11135]

[13] Ryff CD. Psychological well-being revisited: Advances in the science and practice of eudaimonia. Psychotherapy and Psychosomatics. 2014; 83(1):10-28. [DOI:10.1159/000353263] [PMID] [PMCID]

[14] Rubin RB, Rubin AM, Graham E, Perse EM, Seibold D. Communication research measures II: A sourcebook. Routledge; 2010. [DOI:10.4324/9780203871539]

[15] Routledge C, Juhl J. When death thoughts lead to death fears: Mortality salience increases death anxiety for individuals who lack meaning in life. Cognition and Emotion. 2010; 24(5):84854[DOI:10.1080/02699930902847144]

[16] Ross S, Bossis A, Guss J, Agin-Liebes G, Malone T, Cohen B, et al. Rapid and sustained symptom reduction following psilocybin treatment for anxiety and depression in patients with life-threatening cancer: A randomized controlled trial. Journal of Psychopharmacology. 2016 30(12):1165-80. [DOI:10.1177/0269881116675512] [PMID] [PMCID]

[17] Roest AM, Martens EJ, de Jonge P, Denollet J. Anxiety and risk of incident coronary heart disease: A meta-analysis. Journal of the American College of Cardiology. 2010; 56(1):38-46. [DOI:10.1016/j. jacc.2010.03.034] [PMID]

[18] Preston JL, Shin F. Spiritual experiences evoke awe through the small self in both religious and non-religious individuals. Journal of Experimental Social Psychology. 2017; 70:212-21. [DOI:10.1016/j. jesp.2016.11.006

[19] Peters L, Cant R, Payne S, O'Connor M, McDermott F, Hood K, et al. How death anxiety impacts nurses' caring for patients at the end of life: A review of literature. The Open Nursing Journal. 2013; 7:1421. [DOI:10.2174/1874434601307010014] [PMID] [PMCID]

[20] Patel N, Kellezi B, de C Williams AC. Psychological, social and welfare interventions for psychological health and well-being of torture survivors. Cochrane Database of Systematic Reviews. 2014 November. [DOI:10.1002/14651858.CD009317.pub2]

[21] Newberg AB. The neuroscientific study of spiritual practices. Frontiers in Psychology. 2014; 5:215. [DOI:10.3389/fpsyg.2014.00215] [PMID] [PMCID]

[22] Curşeu PL, Ilies R, Vîrgă D, Maricuţoiu L, Sava FA. Personality characteristics that are valued in teams: Not always "more is better"? International Journal of Psychology. 2019; 54(5):638-49. [DOI:10.1002/ijop.12511] [PMID] [PMCID]

[23] McElroy E, Fearon P, Belsky J, Fonagy P, Patalay P. Networks of depression and anxiety symptoms across development. Journal of the American Academy of Child \& Adolescent Psychiatry. 2018; 57(12):964-73. [DOI:10.1016/j.jaac.2018.05.027] [PMID] [PMCID]

[24] Leutner F, Ahmetoglu G, Akhtar R, Chamorro-Premuzic T. The relationship between the entrepreneurial personality and the Big Five personality traits. Personality and Individual Differences. 2014; 63:58-63. [DOI:10.1016/j.paid.2014.01.042]

[25] Underwood LG. The daily spiritual experience scale: Overview and results. Religions. 2011; 2(1):29-50. [DOI:10.3390/rel2010029]

[26] Loustalot F, Wyatt SB, Sims M, Ellison CG, Taylor HA, Underwood L. Psychometric testing of the daily spiritual experiences scale among African Americans in the Jackson Heart Study. Journal of Religion and Health. 2011; 50(3):675-85. [DOI:10.1007/s10943-009-9278-2] [PMID] [PMCID]

[27] Mbaezue N, Mayberry R, Gazmararian J, Quarshie A, Ivonye C Heisler $M$. The impact of health literacy on self-monitoring of blood glucose in patients with diabetes receiving care in an inner-city hospital. Journal of the National Medical Association. 2010 ; 102(1):5-9. [DOI:10.1016/S0027-9684(15)30469-7]

[28] LeDoux JE, Moscarello J, Sears R, Campese V. The birth, death and resurrection of avoidance: A reconceptualization of a troubled paradigm. Molecular Psychiatry. 2017; 22(1):24-36. [DOI:10.1038/ mp.2016.166] [PMID] [PMCID]

[29] Lau RWL, Cheng ST. Gratitude lessens death anxiety. Eur J Ageing 2011; 8(3):169. [DOI:10.1007/s10433-011-0195-3] [PMID] [PMCID]

[30] Krause S, Rydall A, Hales S, Rodin G, Lo C. Initial validation of the death and dying distress scale for the assessment of death anxiety in patients with advanced cancer. J Pain Symptom Manage. 2015; 49(1)126-34. [DOI:10.1016/j.jpainsymman.2014.04.012] 
[31] Kometer M, Pokorny T, Seifritz E, Volleinweider FX. Psilocybininduced spiritual experiences and insightfulness are associated with synchronization of neuronal oscillations. Psychopharmacology (Berl). 2015; 232:3663-76. [DOI:10.1007/s00213-015-4026-7] [PMID]

[32] Kesebir P. A quiet ego quiets death anxiety: Humility as an existential anxiety buffer. J Pers Soc Psychol. 2014; 106(4):610-23. [DOI:10.1037/a0035814] [PMID]

[33] Karam EG, Friedman MJ, Hill ED, Kessler RC, McLaughlin KA, Petukhova $\mathrm{M}$, et al. Cumulative traumas and risk thresholds: 12-month ptsd in the World Mental Health (WMH) surveys. Depress Anxiety. 2014; 31(2):130-42. [DOI:10.1002/da.22169] [PMID] [PMCID]

[34] Iverach L, Menzies RG, Menzies RE. Death anxiety and its role in psychopathology: Reviewing the status of a transdiagnostic construct. Clinical Psychology Review. 2014; 34(7):580-93. [DOI:10.1016/j.cpr.2014.09.002] [PMID]

[35] Hughes DJ, Rowe M, Batey M, Lee A. A tale of two sites: Twitter vs. Facebook and the personality predictors of social media usage. Comput Human Behav. 2012; 28(2):561-9. [DOI:10.1016/j. chb.2011.11.001]

[36] Howell AJ, Dopko RL, Passmore HA, Buro K. Nature connectedness: Associations with well-being and mindfulness. Pers Individ Dif. 2011; 51(2):166-171. [DOI:10.1016/j.paid.2011.03.037]

[37] Herborn KA, Macleod R, Miles WTS, Schofield ANB, Alexander L, Arnold KE. Personality in captivity reflects personality in the wild. Anim Behav. 2010; 79(4):835-43. [DOI:10.1016/j.anbehav.2009.12.026]

[38] Greeson JM, Webber DM, Smoski MJ, Brantley JG, Ekblad AG, Suarez $E C$, et al. Changes in spirituality partly explain health-related quality of life outcomes after mindfulness-based stress reduction. J Behav Med. 2011; 34(6):508-18. [DOI:10.1007/s10865-011-9332-x] [PMID] [PMCID]

[39] Green M, Elliott M. Religion, health, and psychological well-being J Relig Health. 2010; 49:149-63. [DOI:10.1007/s10943-009-9242-1] [PMID]

[40] Goyal M, Singh S, Sibinga EMS, Gould NF, Rowland-Seymour A Sharma R, et al. Meditation Programs for Psychological Stress and Well-being. JAMA Intern Med. 2014; 174(3):357-68. [DOI:10.1001/ jamainternmed.2013.13018] [PMID] [PMCID]

[41] Joshanloo M. Structural and discriminant validity of the tripartite model of mental well-being: Differential relationships with the Big Five traits. Journal of Mental Health. 2019; 28(2):168-74. [DOI:10.1 080/09638237.2017.1370633] [PMID]

[42] Golbeck J, Robles C, Turner K. Predicting personality with social media. In: Conference on Human Factors in Computing Systems Proceedings. SIGCHI, 2011. [DOI:10.1145/1979742.1979614] 
